\section{JURNAL EKONOMI EFEKTIF}

ISSN : $2622-8882$, E-ISSN : 2622-9935

Jurnal Ekonomi Efektif, Vol. 4, No. 1, Oktober 2021 @Prodi Manajemen Fakultas Ekonomi Universitas Pamulang

\title{
PENGARUH PELATIHAN DAN KOMPENSASI TERHADAP PRESTASI KERJA YANG BERDAMPAK PADA KINERJA KARYAWAN PADA PT CIPTA MEGA SARANA DI JAKARTA
}

\author{
Anggada Bayu Seta ${ }^{*}$, Denok Sunarsi ${ }^{2}$, Nurjaya ${ }^{3}$, Muhamad Saddam $^{4}$, Ridwan Faroji ${ }^{5}$ \\ ${ }^{1.2}$ Universitas Pamulang, Tangerang Selatan, Banten, Indonesia \\ ${ }^{3}$ Universitas Suryakancana, Cianjur, Jawa Barat, Indonesia \\ ${ }^{4.5}$ Sekolah Tinggi Ilmu Ekonomi Hidayatullah Depok, Jawa Barat, Indonesia \\ dosen02245@unpam.ac.id*
}

Manuskrip: Oktober -2021; Ditinjau: Oktober: -2021; Diterima: Oktober-2021; Online: Oktober-2021;

Diterbitkan: Oktober-2021

\begin{abstract}
ABSTRAK
Penelitian ini bertujuan untuk mengetahui pengaruh pelatihan dan kompensasi terhadap prestasi kerja yang berdampak pada kinerja karyawan pada PT. Cipta Mega Sarana di Jakarta. Metode yang digunakan adalah explanatory research dengan sampel sebanyak 112 responden. Teknik analisis menggunakan analisis statistik dengan pengujian regresi, korelasi, determinasi dan uji hipotesis. Hasil penelitian ini pelatihan dan kompensasi secara simultan berpengaruh signifikan terhadap prestasi kerja sebesar $52,4 \%$, uji hipotesis diperoleh signifikansi $0,000<$ 0,05.Prestasi kerja berpengaruh signifikan terhadap kinerja karyawan sebesar 40,0\%, uji hipotesis diperoleh signifikansi $0,000<0,05$.
\end{abstract}

Kata Kunci: Pelatihan, Kompensasi, Prestasi kerja, Kinerja Karyawan

\section{ABSTRACT}

This study aims to determine the effect of training and compensation on work performance which has an impact on employee performance at PT. Cipta Mega Sarana in Jakarta. The method used is explanatory research with a sample of 112 respondents. The analysis technique uses statistical analysis with regression, correlation, determination and hypothesis testing. The results of this study that simultaneous training and compensation have a significant effect on work performance by 52.4\%, hypothesis testing obtained a significance of $0.000<0.05$. Work achievement has a significant effect on employee performance by $40.0 \%$, hypothesis testing obtained a significance of $0.000<0.05$.

Keywords: Training, Compensation, Job Performance, Employee Performance 


\section{PENDAHULUAN}

\section{A. Latar Belakang Masalah}

Sumber daya yang dimiliki oleh perusahaan dapat dikategorikan atas empat tipe sumber daya, yaitu finansial, fisik, manusia, kemampuan teknologi dan sistem (Simamora, 2001:2). Sumber daya manusia adalah mahluk yang sadar diri, ini berarti bahwa faktor tersebut adalah satu-satunya mahluk hidup yang mempunyai pengetahuan atas kehadiran sendiri. Artinya sumber daya manusia mampu mempelajari, menganalisis, mengetahui dan menilai dirinya.

Untuk meningkatkan efisiensi antara lain diperlukan sumber daya manusia (SDM) yang berkualitas. Arti penting sumber daya manusia dalam suatu perusahaan adalah bermuara dari kenyataan bahwa orang-orang (manusia) merupakan elemen yang selalu ada di dalam setiap organisasi. Mereka membuat tujuan-tujuan, inovasi, dan mencapai tujuan-tujuan organisasi. Sumber daya manusia memberikan cetusan kreatif di setiap organisasi. Tanpa orang-orang yang kreatif, tampaknya mustahil bagi organisasi untuk meraih tujuan-tujuannya. Sumber daya manusia membuat sumbersumber daya organisasi lainnya berjalan. Tidak ada satupun faktor dalam kegiatankegiatan bisnis mempunyai dampak langsung pada kesejahteraan perusahaan perusahaan selain dari pada sumber daya manusia itu sendiri.

Pada hakekatnya, manajer membuat segala sesuatu dilakukan melalui upaya orang-orang lain, yang membutuhkan pengelolaan sumber daya manusia yang efektif. Manajemen sumber daya manusia yang efektif mengharuskan manajer menemukan cara terbaik dalam mengkaryakan orang- orang agar mencapai tujuan perusahaan dan meningkatkan kinerja organisasi serta prestasi kerja karyawan dibandingkan organisasi atau perusahaan lain.

Berdirinya suatu perusahaan tidak terlepas dari sumber daya manusia yang ada di dalamnya. Begitupula dengan PT. Cipta Mega Sarana tentunya mempunyai tujuan mendapatkan profit atau keuntungan yang maksimal bagi perusahaan, diperlukan manajemen sumber daya manusia yang efektif untuk meningkatkan prestasi karyawan dalam perusahaan tersebut.

Salah satu cara untuk meningkatkan kinerja, perusahaan adalah melalui pelatihan. Pelatihan adalah suatu proses dimana orang-orang mencapai kemampuan tertentu untuk membantu pencapaian tujuan organisai (Malthis \& Jackson, 2002:5). Training adalah proses sistematik pengubahan perilaku para karyawan dalam suatu arah guna meningkatkan tujuan organisasional (Simamora, 1997:342).

Pelatihan membantu organisasi untuk mencapai tujuan-tujuannya dalam memperoleh, memelihara dan mempertahan kualitas kerja yang produktif, sehingga kinerja karyawan yang efektif dapat terwujud.

Tidak hanya pelatihan sebagai penunjang terjadinya prestasi kerja, kompensasi juga menjadi faktor pendukung untuk karyawan bekerja lebih maksimal guna memperoleh prestasi kerja dalam perusahaan. Kompensasi adalah segala sesuatu yang diterima para karyawan sebagai balas jasa untuk kerja mereka (Handoko, 2001:155). Kompensasi meliputi kembalian-kembalian finansial, jasa-jasa wujud dan tunjangantunjangan yang diterima oleh para karyawan sebagai bagian dari hubungan kepegawaian. Kompensasi merupakan apa yang diterima oleh karyawan sebagai ganti distribusi kepada organisasi atau perusahaan, kompensasi mampu membantu suatu organisasi atau perusahaan untuk mencapai tujuan-tujuannya.

Pemberian pelatihan dan kompensasi yang memadai dalam suatu perusahaan memiliki keterkaitan yang erat dengan motivasi kerja karyawan. Semakin tepat kesesuaian antara beban kerja dan tanggung jawab terhadap pelatihan dan kompensasi 
yang diperoleh, maka semakin termotivasi karyawan dalam bekerja, juga semakin termotivasi karyawan dalam bekerja maka akan menghasilkan prestasi kerja dalam perusahaan, sehingga tercipta kinerja yang baik.

Berdasarkan uraian pada latar belakang di atas, maka penulis membuat judul penelitian "Pengaruh Pelatihan Dan Kompensasi Terhadap Prestasi Kerja Yang Berdampak Pada Kinerja Karyawan Pada PT. Cipta Mega Sarana di Jakarta".

\section{B. Rumusan Masalah}

1. Adakah pengaruh secara parsial antara pelatihan terhadap prestasi kerja pada PT. Cipta Mega Sarana di Jakarta?.

2. Adakah pengaruh secara parsial antara kompensasi terhadap prestasi kerja pada PT. Cipta Mega Sarana di Jakarta?.

3. Adakah pengaruh secara simultan antara pelatihan dan kompensasi terhadap prestasi kerja pada PT. Cipta Mega Sarana di Jakarta ?.

4. Adakah pengaruh antara prestasi kerja terhadap kinerja karyawan pada PT. Cipta Mega Sarana di Jakarta?.

\section{Tujuan Penelitian}

1. Untuk mengetahui pengaruh secara parsial antara pelatihan terhadap prestasi kerja pada PT. Cipta Mega Sarana di Jakarta .

2. Untuk mengetahui pengaruh secara parsial antara kompensasi terhadap prestasi kerja pada PT. Cipta Mega Sarana di Jakarta.

3. Untuk mengetahui pengaruh secara simultan antara pelatihan dan kompensasi terhadap prestasi kerja pada PT. Cipta Mega Sarana di Jakarta.

4. Untuk mengetahui pengaruh antara prestasi kerja terhadap kinerja karyawan pada PT. Cipta Mega Sarana di Jakarta.

\section{TINJAUAN PUSTAKA}

\section{Pelatihan}

Menurut Sutrisno (2016) mendefinisikan "Pelatihan adalah perilaku seseorang yang sesuai dengan peraturan, prosedur kerja yang ada atau sikap dan tingkah laku serta perbuatan yang sesuai dengan peraturan dari organisasi baik tertulis maupun tidak tertulis". Dalam penelitian ini indikator yang digunakan meliputi: taat terhadap aturan waktu taat terhadap aturan organisasi, taat terhadap aturan perilaku dalam pekerjaan, taat terhadap peraturan lainnya.

\section{Kompensasi}

Menurut Simamora (2018:445) menjelaskan bahwa "Kompensasi adalah semua pemberian perusahaan kepada karyawan sebagai imbalan atau balas jasa atas jasa yang diberikan karyawan kepada perusahaan"

\section{Prestasi kerja}

Menurut Mangkunegara (2019:67) menyatakan Prestasi kerja adalah hasil kerja secara kualitas dan kuantitas yang dicapai oleh seseorang karyawan dalam melaksanakan tugasnya sesuai dengan tanggung jawab yang diberikan kepadanya.

\section{Kinerja Karyawan}

Menurut Mangkunegara (2019:75) pengertian kinerja adalah hasil kerja secara kualitas dan kuantitas yang dicapai oleh seorang pegawai dalam melaksanakan tugasnya 
sesuai dengan tanggung jawab yang diberikan kepadanya. Adapun indikator yang digunakan sebagai berikut:

\section{Model Penelitian}

Menurut pendapat Sugiyono (2018) "Model penelitian merupakan sintesa yang mencerminkan keterkaitan antara variabel yang diteliti dan merupakan tuntunan untuk memecahkan masalah penelitian serta merumuskan hipotesis yang berbentuk bagan alur yang dilengkapi penjelasan kualitatif". Dalam penelitian ini model penelitian yang dibuat sebagai berikut:

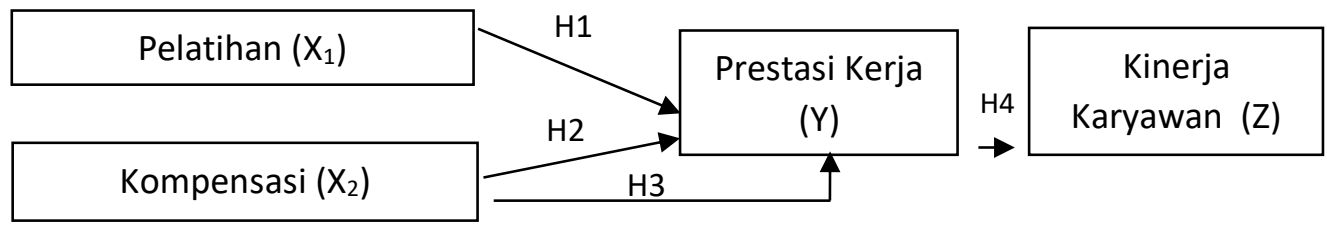

Gambar 1. Paradigma Model Penelitian

\section{Hipotesis Penelitian}

Menurut Sugiyono (2018) "Hipotesis merupakan jawaban sementara terhadap masalah-masalah, karena sifatnya sementara maka perlu dibuktikan kebenarannya melalui data empirik yang terkumpul". Adapun rumusan hipotesis yang diajukan sebagai berikut:

H1 : Terdapat pengaruh yang signifikan pelatihan terhadap prestasi kerja pada PT. Cipta Mega Sarana di Jakarta.

H2 : Terdapat pengaruh yang signifikan kompensasi terhadap prestasi kerja pada PT. Cipta Mega Sarana di Jakarta.

H3 : Terdapat pengaruh yang signifikan pelatihan dan kompensasi secara simultan terhadap prestasi kerja pada PT. Cipta Mega Sarana di Jakarta.

H4 : Terdapat pengaruh yang signifikan prestasi kerja terhadap kinerja karyawan pada PT. Cipta Mega Sarana di Jakarta.

\section{METODE PENELITIAN}

\section{Populasi} di Jakarta

Populasi dalam penelitian ini berjumlah 112 responden PT. Cipta Mega Sarana

\section{Sampel}

Teknik pengambilan sampling dalam penelitian ini adalah samplel jenuh, dimana semua anggota populasi dijasikan sebagai sampel. Dengan demikian sampel dalam penelitian ini berjumlah 112 responden.

\section{Jenis Penelitian}

Jenis penelitian yang dipakai adalah asosiatif, dimana tujuannya adalah untuk mengetahui mencari keterhubungan antara

\section{Teknik Analisis Data}

Dalam menganalisis data digunakan uji instrumen, uji asumsi klasik, regresi, koefisien determinasi dan uji hipotesis.

\section{a. Uji Instrumen}

Pada pengujian ini digunakan uji validitas dan uji reliabilitas.

1) Uji Validitas.

Uji validitas dimaksudkan untuk mengetahui ketepatan data tentang 
kesesuaian antara yang mau diukur dengan hasil pengukurannya. Untuk melakukan uji validitas dilihat nilai signifikansi 2 tailed dibandingkan dengan 0,05 dengan dengan ketentuan:

(a)Jika nilai signifikansi 2 talied $<0,05$, maka instrumen valid,

(b)Jika nilai signifikansi 2 talied $>0,05$, maka instrumen tidak valid,

2) Uji Reliabilitas.

Uji reliabilitas merupakan serangkaian pengukuran atau serangkaian alat ukur yang memiliki konsistensi bila pengukuran yang dilakukan dengan alat ukur itu dilakukan secara berulang. Instrumen yang baik tidak akan bersifat tendensius mengarahkan responden untuk memilih jawaban tertentu. Adapun kriteria yang digunakan sebagai berikut:

(a)Jika Cronbach's Alpha >0,600, maka instrumen reliabel.

(b)Jika Cronbach's Alpha < 0,600, maka instrumen tidak reliabel.

\section{b. Uji Asumsi Klasik}

Uji asumsi klasik dimaksudkan untuk mengetahui ketepatan sebuah data. Dalam penelitian ini uji asumsi klasik yang digunakan adalah meliputi: Uji Normalitas, Uji Multikolinearitas, Uji Autokorelasi, dan Uji Heterokedastisitas. Adapun hasilnya sebagai berikut:

1) Uji Normalitas

Uji normalitas digunakan untuk menguji apakah dalam sebuah model regresi, variabel dependen, variabel independen, atau keduanya mempunyai distribusi normal atau tidak. Uji normilitas menggunakan Kolmogorov-Smirnov test, dengan ketentuan:

(a) Jika nilai signifikansi $<0,05$, maka data tidak berdistribusi normal.

(b)Jika nilai signifikansi $>0,05$, maka data berdistribusi normal.

2) Uji Multikolinieritas

Uji Multikolinieritas ini bertujuan menguji apakah pada model regresi ditemukan adanya korelasi antar variabel independen. Dalam penelitian ini digunakan batas tolerance dan lawannya, variance inflation factor (VIF) dengan ketentuan:

(a) Jika nilai nilai tolerance lebih $<1$ dan nilai Variance Inflation Factor (VIF) $<$ dari 1, maka tidak terjadi multikolinieritas.

(b)Jika nilai nilai tolerance lebih > 1 dan nilai Variance Inflation Factor (VIF) > dari 1, maka terjadi multikolinieritas.

3) Uji Autokorelasi

Uji autokorelasi digunakan untuk mengetahui ada atau tidaknya penyimpangan asumsi klasik autokorelasi, yaitu adanya korelasi antar anggota sampel. Dalam penelitian ini digunakan Durbin Watson Test.

4) Uji Heterskedastisitas

Uji Htereoskaedastisitas bertujuan untuk mengetahui apakah dalam model regresi terjadi ketidaksamaan varian dari suatu residual pengamatan ke pengamatan lain. Cara menprediksi ada atau tidaknya heteroskedastisitas digunakan Glejser Test. 


\section{c. Uji Statistik}

1) Regresi Linier

Analisis regresi liner merupakan suatu teknik statistika yang digunakan untuk mencari persamaan regresi yang bermanfaat untuk meramal nilai variabel dependen berdasarkan nilai-nilai variabel independen. Dalam penelitian ini digunakan regresi linier berganda.

2) Koefisien Korelasi

Pengujian koefisien korelasi dimaksudkan untuk mengetahui tingkat kekuatan hubungan antara variabel independen dengan variabel dependen baik secara parsial maupun simultan".

3) Koefisien Determinasi

Analisis koefisien determinasi dimaksudkan untuk mengetahui besarnya pengaruh antara variabel independen terhadap variabel dependen baik secara parsial maupun simultan.

4) Uji Hipotesis

Pengujian hipotesis dimaksudkan untuk menentukan apakah suatu hipotesis sebaiknya diterima atau ditolak. Dalam penelitian ini digunakan uji t (Parsial) dan uji F (Simultan).

\section{HASIL PENELITIAN}

\section{Hasil Uji Instrumen}

a. Dari hasil pengujian diperoleh seluruh item kuesioner variabel pelatihan diperoleh nilai signifikansi 2 tailed sebesar $0,000<0,05$, dengan demikian instrumen valid.

b. Dari hasil pengujian diperoleh seluruh item kuesioner variabel kompensasi diperoleh nilai signifikansi 2 tailed sebesar $0,000<0,05$, dengan demikian instrumen valid.

c. Dari hasil pengujian diperoleh seluruh item kuesioner variabel prestasi kerja diperoleh nilai signifikansi 2 tailed sebesar $0,000<0,05$, dengan demikian instrumen valid.

d. Dari hasil pengujian reliabilitas, diperoleh hasil sebagai berikut:

Tabel 1. Hasil Pengujian Reliabilitas

\begin{tabular}{|c|c|c|c|}
\hline Variabel & $\begin{array}{c}\text { Cronbach's } \\
\text { Alpha }\end{array}$ & $\begin{array}{c}\text { Standar Kritis } \\
\text { Alpha }\end{array}$ & Keterangan \\
\hline Pelatihan (X1) & 0,628 & 0,600 & Reliabel \\
\hline Kompensasi (X2) & 0,632 & 0,600 & Reliabel \\
\hline Prestasi Kerja (Y) & 0,618 & 0,600 & Reliabel \\
\hline Kinerja Karyawan (Z) & 0,631 & 0,600 & Reliabel \\
\hline
\end{tabular}

Berdasarkan hasil pengujuan di atas, keseluruhan variabel pelatihan (X1), kompensasi (X2), Prestasi kerja (Y) dan Kinerja Karyawan (Z) diperoleh nilai cronbach alpha lebih besar dari 0,600. Dengan demikian dinyatakan reliabel.

\section{Hasil Uji Asumsi Klasik}

\section{a. Uji Normalitas}

Hasil uji normalitas dengan alat uji Kolmogorov-Smirnov Test, sebagai berikut: 
Tabel 2. Hasil Normalitas Kolmogorov-Smirnov Test

Tests of Normality

Kolmogorov-Smirnov ${ }^{\mathrm{a}}$

Shapiro-Wilk

Statistic

Prestasi kerja (Y)

\begin{tabular}{l|r|r|r}
.073 & 112 & .192 \\
\hline
\end{tabular}
Statistic

*. This is a lower bound of the true significance.

a. Lilliefors Significance Correction

Berdasarkan hasil pengujian pada tabel di atas diperoleh nilai signifikansi 0,200 dimana nilai tersebut lebih besar dari nilai $\alpha=0,050$ atau $(0,200>0,050)$. Dengan demikian maka asumsi distribusi persamaan pada uji ini adalah normal.

\section{b. Uji Multikonilieritas}

Uji multikolinearitas dilakukan dengan melihat nilai Tolerance Value dan Variance Inflation Factor (VIF). Adapun hasil pengujiannya sebagai berikut:

Tabel 3. Hasil Uji Multikolinieritas dengan Collinierity Statistic.

\section{Coefficients ${ }^{\mathrm{a}}$}

Unstandardized

Coefficients

\begin{tabular}{llr|rr|r|r}
\multicolumn{2}{l}{ Model } & \multicolumn{2}{c}{ B } & Std. Error & Coefficients & \multicolumn{2}{c}{ Statistics } \\
\hline 1 & (Constant) & 7.717 & 2.855 & & Tolerance & VIF \\
\cline { 2 - 7 } & Pelatihan (X1) & .490 & .075 & .494 & .772 & 1.295 \\
\hline \multicolumn{2}{|c|}{ Kompensasi (X2) } & .323 & .071 & .343 & .772 & 1.295 \\
\hline
\end{tabular}

a. Dependent Variable: Prestasi kerja (Y)

Berdasarkan hasil pengujian pada tabel di atas nilai tolerance masing-masing variabel bebas yaitu 0,772 < 1,0 dan nilai Variance Inflation Factor (VIF) sebesar $1,295<10$, dengan demikian model regresi ini tidak terjadi multikolinearitas.

\section{c. Uji Autokorelasi}

Pengujian dilakukan dengan alat uji Darbin-Watson (DW test). Adapun hasil pengujiannya sebagai berikut:

\begin{tabular}{lc|r|r|r|r}
\multicolumn{7}{c}{} & \multicolumn{3}{c}{ Tabel 4. Hasil Uji Autokorelasi } \\
Model Summary \\
Model & R & R Square & $\begin{array}{c}\text { Adjusted R } \\
\text { Square }\end{array}$ & $\begin{array}{c}\text { Std. Error of } \\
\text { the Estimate }\end{array}$ & Durbin-Watson \\
\hline 1 & $.724^{\mathrm{a}}$ & .524 & .515 & 2.397 & 1.654 \\
\hline
\end{tabular}

a. Predictors: (Constant), Kompensasi (X2), Pelatihan (X1)

b. Dependent Variable: Prestasi kerja (Y)

Hasil pengujian pada tabel di atas diperoleh nilai Durbin-Watson sebesar 1,654 nilai tersebut berada diantara interval $1.550-2.460$. Dengan demikian model regresi dinyatakan tidak ada gangguan autokorelasi.

\section{d. Uji Heteroskesdastisitas}

Pengujian dilakukan dengan alat uji Glejser Test Model. Adapun hasil pengujiannya sebagai berikut:

Tabel 5. Hasil Uji Heteroskesdastisitas dengan Glejser Test Model

\section{Coefficients ${ }^{\mathrm{a}}$}

Unstandardized

Coefficients

\begin{tabular}{|c|c|c|c|c|c|}
\hline \multirow{2}{*}{ Model } & \multicolumn{2}{|r|}{ Ictents } & \multirow{2}{*}{ Beta } & \multirow[b]{2}{*}{$\mathrm{t}$} & \multirow[b]{2}{*}{ Sig. } \\
\hline & $\mathrm{B}$ & Std. Error & & & \\
\hline 1 (Constant) & 1.963 & 1.684 & & 1.165 & .246 \\
\hline Pelatihan (X1) & .035 & .044 & .085 & .786 & .433 \\
\hline Kompensasi (X2) & -.036 & .042 & -.095 & -.872 & 385 \\
\hline
\end{tabular}

a. Dependent Variable: RES2 
Hasil pengujian dengan menggunakan uji glejser diperoleh nilai Sig. > 0,050. Dengan demikian regression model tidak ada gangguan heteroskesdastisitas.

\section{Analisis Deskriptif}

Pada pengujian ini digunakan untuk mengetahui skor minimum dan maksimum skor tertinggi, ratting score dan standar deviasi dari masing-masing variabel. Adapun hasilnya sebagai berikut:

Tabel 6. Hasil Analisis Descriptive Statistics

\section{Descriptive Statistics}

\begin{tabular}{ll|r|r|r|r} 
& N & Minimum & Maximum & Mean & Std. Deviation \\
\hline Pelatihan (X1) & 112 & 30 & 46 & 38.35 & 3.466 \\
\hline Kompensasi (X2) & 112 & 30 & 46 & 38.08 & 3.657 \\
\hline Prestasi kerja (Y) & 112 & 32 & 45 & 38.84 & 3.442 \\
\hline Kinerja Karyawan (Z) & 112 & 31 & 50 & 39.14 & 3.551 \\
\hline Valid N (listwise) & 112 & & & & \\
\hline
\end{tabular}

Pelatihan diperoleh varians minimum sebesar 30 dan varians maximum 46 dengan ratting score sebesar 3,835 dengan standar deviasi 3,4666.

Kompensasi diperoleh varians minimum sebesar 30 dan varians maximum 46 dengan ratting score sebesar 3,808 dengan standar deviasi 3,657.

Prestasi kerja diperoleh varians minimum sebesar 32 dan varians maximum 45 dengan ratting score sebesar 3,884 dengan standar deviasi 3,442

Kinerja karyawan diperoleh varians minimum sebesar 31 dan varians maximum 50 dengan ratting score sebesar 3,914 dengan standar deviasi 3,551.

\section{Analisis Kuantitatif}

Pada analisis ini dimaksudkan untuk mengetahui pengaruh variabel independen terhadap variabel dependen. Adapun hasil pengujian sebagai berikut:

\section{a. Analisis Regresi Linier Berganda}

Uji regresi ini dimaksudkan untuk mengetahui perubahan variabel dependen jika variabel independen mengalami perubahan. Adapun hasil pengujiannya sebagai berikut:

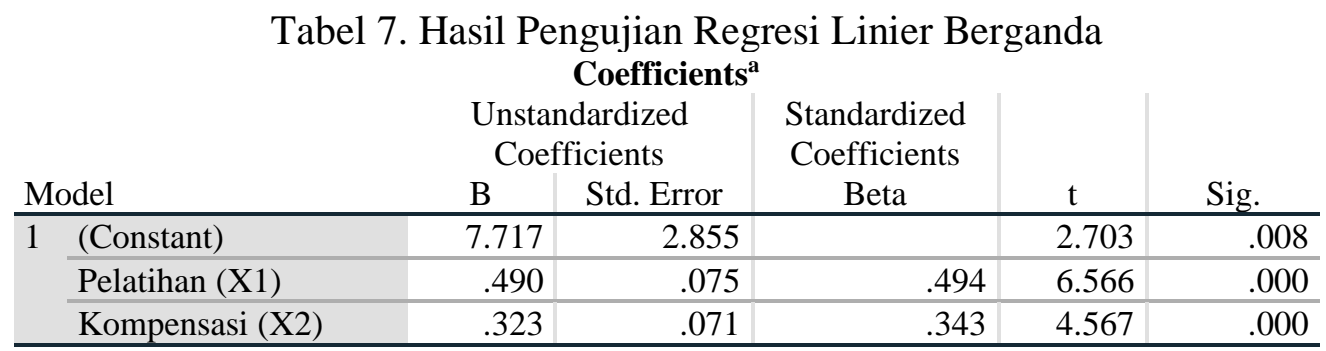

a. Dependent Variable: Prestasi kerja (Y)

Berdasarkan hasil pengujian pada tabel di atas, diperoleh persamaan regresi $Y$ $=7,717+0,490 \mathrm{X} 1+0,323 \mathrm{X} 2$. Dari persamaan tersebut dijelaskan sebagai berikut:

1) Konstanta sebesar 7,717 diartikan jika pelatihan dan kompensasi tidak ada, maka telah terdapat nilai prestasi kerja sebesar 7,717 point.

2) Koefisien regresi pelatihan sebesar 0,490 , angka ini positif artinya setiap ada peningkatan pelatihan sebesar 0,490 point maka prestasi kerja juga akan mengalami peningkatan sebesar 0,490 point.

3) Koefisien regresi kompensasi sebesar 0,323, angka ini positif artinya setiap ada peningkatan kompensasi sebesar 0,323 point maka prestasi kerja juga akan mengalami peningkatan sebesar 0,323 point 


\section{b. Analisis Koefisien Determinasi}

Analisis koefisien determinasi dimaksudkan untuk mengetahui besarnya persentase pengaruh dari variabel independen terhadap variabel dependen baik secara parsial maupun simultan. Adapun hasil pengujian sebagai berikut:

Tabel 8. Hasil Pengujian Koefisien Determinasi Pelatihan Terhadap Prestasi kerja.

Model Summary

\begin{tabular}{|c|c|c|c|c|}
\hline Mode & $\mathrm{R}$ & R Square & $\begin{array}{l}\text { Adjusted R } \\
\text { Square }\end{array}$ & $\begin{array}{l}\text { Std. Error of the } \\
\text { Estimate }\end{array}$ \\
\hline 1 & $.658^{\mathrm{a}}$ & .433 & .428 & 2.604 \\
\hline
\end{tabular}

a. Predictors: (Constant), Pelatihan (X1)

Berdasarkan hasil pengujian diperoleh nilai determinasi sebesar 0,433 artinya pelatihan memiliki kontribusi pengaruh sebesar $43,3 \%$ terhadap prestasi kerja.

Tabel 9. Hasil Pengujian Koefisien Determinasi Kompensasi Terhadap Prestasi kerja.

Model Summary

\begin{tabular}{|c|c|c|c|c|}
\hline \multirow[b]{2}{*}{ Model } & \multicolumn{3}{|c|}{ Model Summary } & \multirow[b]{2}{*}{$\begin{array}{l}\text { Std. Error of the } \\
\text { Estimate }\end{array}$} \\
\hline & $\mathrm{R}$ & R Square & $\begin{array}{l}\text { Adjusted R } \\
\text { Square }\end{array}$ & \\
\hline$\overline{1}$ & $.579^{\mathrm{a}}$ & .336 & .330 & 2.818 \\
\hline
\end{tabular}

a. Predictors: (Constant), Kompensasi (X2)

Berdasarkan hasil pengujian diperoleh nilai determinasi sebesar 0,336 artinya kompensasi memiliki kontribusi pengaruh sebesar 33,6\% terhadap prestasi kerja.

Tabel 10. Hasil Pengujian Koefisien Determinasi Pelatihan Dan Kompensasi Secara Simultan Terhadap Prestasi kerja.

Model Summary

\begin{tabular}{|c|c|c|c|c|}
\hline \multicolumn{5}{|c|}{ Model Summary } \\
\hline Model & $\mathrm{R}$ & R Square & $\begin{array}{l}\text { Adjusted R } \\
\text { Square }\end{array}$ & $\begin{array}{l}\text { Std. Error of the } \\
\text { Estimate }\end{array}$ \\
\hline 1 & $.724^{\mathrm{a}}$ & .524 & .515 & 2.397 \\
\hline
\end{tabular}

a. Predictors: (Constant), Kompensasi (X2), Pelatihan (X1)

Berdasarkan hasil pengujian diperoleh nilai determinasi sebesar 0,524 artinya pelatihan dan kompensasi secera simultan memiliki kontribusi pengaruh sebesar $52,4 \%$ terhadap prestasi kerja, sedangkan sisanya sebesar 47,6\% dipengaruhi faktor lain.

Tabel 11. Hasil Pengujian Koefisien Determinasi Prestasi kerja Terhadap Kinerja

\section{Karyawan.}

\section{Model Summary}

\begin{tabular}{|c|c|c|c|c|}
\hline \\
\hline Model & $\mathrm{R}$ & R Square & $\begin{array}{l}\text { Adjusted R } \\
\text { Square }\end{array}$ & $\begin{array}{l}\text { Std. Error of the } \\
\text { Estimate }\end{array}$ \\
\hline$\overline{1}$ & $.633^{\mathrm{a}}$ & .400 & .395 & 2.762 \\
\hline
\end{tabular}

Berdasarkan hasil pengujian diperoleh nilai determinasi sebesar 0,400 artinya prestasi kerja memiliki kontribusi pengaruh sebesar 40,0\% terhadap kinerja karyawan.

\section{c. Uji Hipotesis}

\section{Uji hipotesis Parsial (Uji t)}

Pengujian hipotesis dengan uji t digunakan untuk mengetahui hipotesis parsial mana yang diterima. Adapun hasil pengujian sebagai berikut:

Tabel 12. Hasil Uji Hipotesis Pelatihan Terhadap Prestasi kerja.

\begin{tabular}{|c|c|c|c|c|c|}
\hline \multirow[b]{3}{*}{ del } & \multicolumn{2}{|c|}{ Coefficients $^{\mathrm{a}}$} & \multirow[b]{2}{*}{$\begin{array}{l}\text { Standardized } \\
\text { Coefficients }\end{array}$} & & \multirow[b]{3}{*}{ Sig. } \\
\hline & $\begin{array}{l}\text { Unstan } \\
\text { Coeff }\end{array}$ & $\begin{array}{l}\text { ardized } \\
\text { cients }\end{array}$ & & & \\
\hline & B & Std. Error & Beta & $\mathrm{t}$ & \\
\hline $\begin{array}{ll}1 \text { (Constant) } \\
\end{array}$ & 13.782 & 2.746 & & 5.020 & .000 \\
\hline
\end{tabular}




\begin{tabular}{|l|l|l|l|l|r|}
\hline Pelatihan $(\mathrm{X} 1)$ & .653 & .071 & .658 & 9.163 & .000 \\
\hline
\end{tabular}

a. Dependent Variable: Prestasi kerja (Y)

Berdasarkan hasil pengujian pada tabel di atas, diperoleh nilai thitung $>\mathrm{t}$ tabel atau $(9,163>1,982)$, dengan demikian hipotesis yang diajukan bahwa terdapat pengaruh yang signifikan antara pelatihan terhadap prestasi kerja diterima.

Tabel 13. Hasil Uji Hipotesis Kompensasi Terhadap Prestasi kerja.

$$
\text { Coefficients }^{\text {a }}
$$

Unstandardized

Coefficients

\begin{tabular}{|c|c|c|c|c|c|}
\hline \multirow[b]{2}{*}{ Model } & \multicolumn{2}{|c|}{ Coefficients } & \multirow{2}{*}{$\begin{array}{c}\text { Coefficients } \\
\text { Beta }\end{array}$} & \multirow[b]{2}{*}{$\mathrm{t}$} & \multirow[b]{2}{*}{ Sig. } \\
\hline & B & Std. Error & & & \\
\hline 1 (Constant) & 18.072 & 2.798 & & 6.458 & .000 \\
\hline Kompensasi (X2) & .545 & .073 & .579 & 7.455 & .000 \\
\hline
\end{tabular}

a. Dependent Variable: Prestasi kerja (Y)

Berdasarkan hasil pengujian pada tabel di atas, diperoleh nilai t hitung $>\mathrm{t}$ tabel atau $(7,455>1,982)$, dengan demikian hipotesis yang diajukan bahwa terdapat pengaruh yang signifikan antara kompensasi terhadap prestasi kerja diterima.

Tabel 14. Hasil Uji Hipotesis Prestasi kerja Terhadap Kinerja Karyawan.

\section{Coefficients $^{\mathrm{a}}$}

Unstandardized

Coefficients

\begin{tabular}{llr|r|r|r|r}
\multicolumn{1}{l}{ Model } & \multicolumn{2}{c|}{ B } & Std. Error & Beta & \multicolumn{1}{c|}{ t } & \multicolumn{1}{c}{ Sig. } \\
\hline \multirow{2}{*}{1} & (Constant) & 13.787 & 2.970 & & 4.642 & .000 \\
\cline { 2 - 8 } & Prestasi kerja (Y) & .653 & .076 & .633 & 8.572 & .000 \\
\hline
\end{tabular}

a. Dependent Variable: Kinerja Karyawan (Z)

Berdasarkan hasil pengujian pada tabel di atas, diperoleh nilai t hitung $>\mathrm{t}$ tabel atau $(8,572>1,982)$, dengan demikian hipotesis yang diajukan bahwa terdapat pengaruh yang signifikan antara prestasi kerja terhadap kinerja karyawan diterima.

\section{Uji Hipotesis Simultan (Uji F)}

Pengujian hipotesis dengan uji $\mathrm{F}$ digunakan untuk mengetahui hipotesis simultan yang mana yang diterima.

Hipotesis ketiga: Terdapat pengaruh yang signifikan antara pelatihan, kompensasi dan motivasi terhadap prestasi kerja.

Tabel 15. Hasil Uji Hipotesis Pelatihan dan Kompensasi Secara Simultan Terhadap Prestasi kerja.

\begin{tabular}{|c|c|c|c|c|c|c|}
\hline \multicolumn{7}{|c|}{ ANOVA $^{\mathrm{a}}$} \\
\hline \multirow{2}{*}{\multicolumn{2}{|c|}{$\begin{array}{l}\text { Model } \\
\text { Regression }\end{array}$}} & Sum of Squares & df & Mean Square & $\mathrm{F}$ & Sig. \\
\hline & Regression & 689.066 & 2 & 344.533 & 59.987 & $.000^{\mathrm{b}}$ \\
\hline & Residual & 626.041 & 109 & 5.743 & & \\
\hline & Total & 1315.107 & 111 & & & \\
\hline
\end{tabular}

a. Dependent Variable: Prestasi kerja (Y)

b. Predictors: (Constant), Kompensasi (X2), Pelatihan (X1)

Berdasarkan hasil pengujian pada tabel di atas, diperoleh nilai $\mathrm{F}$ hitung $>\mathrm{F}$ tabel atau $(59,987>2,690)$, dengan demikian hipotesis keempat yang diajukan bahwa terdapat pengaruh yang signifikan antara pelatihan dan kompensasi secara simultan terhadap prestasi kerja diterima.

\section{Pembahasan Hasil Penelitian}

\section{Pengaruh Pelatihan Terhadap Prestasi kerja}

Pelatihan berpengaruh signifikan terhadap prestasi kerja dengan nilai koefisien determinasi sebesar 43,3\%. Pengujian hipotesis diperoleh nilai t hitung $>\mathrm{t}$ tabel atau $(9,163>1,982)$. Dengan demikian hipotesis yang diajukan bahwa terdapat berpengaruh 
signifikan antara pelatihan terhadap prestasi kerja diterima.

\section{Pengaruh Kompensasi Terhadap Prestasi kerja}

Kompensasi berpengaruh signifikan terhadap prestasi kerja dengan nilai koefisien determinasi sebesar 33,6\%. Pengujian hipotesis diperoleh nilai t hitung $>t$ tabel atau $(7,455>1,982)$. Dengan demikian hipotesis yang diajukan bahwa terdapat berpengaruh signifikan antara kompensasi terhadap prestasi kerja diterima.

\section{Pengaruh Pelatihan Dan Kompensasi Terhadap Prestasi kerja}

Pelatihan dan kompensasi berpengaruh signifikan terhadap prestasi kerja dengan diperoleh persamaan regresi $\mathrm{Y}=7,717+0,490 \mathrm{X} 1+0,323 \mathrm{X} 2$, dengan nilai koefisien determinasi sebesar 52,4\% sedangkan sisanya sebesar 47,6\% dipengaruhi faktor lain. Pengujian hipotesis diperoleh nilai $\mathrm{F}$ hitung $>\mathrm{F}$ tabel atau $(59,987>2,690)$. Dengan demikian hipotesis yang diajukan bahwa terdapat berpengaruh signifikan antara pelatihan dan kompensasi terhadap prestasi kerja diterima.

\section{Pengaruh Prestasi kerja Terhadap Kinerja Karyawan}

Prestasi kerja berpengaruh signifikan terhadap kinerja karyawan dengan nilai koefisien determinasi sebesar 40,0\%. Pengujian hipotesis diperoleh nilai $t$ hitung $>\mathrm{t}$ tabel atau $(8,572>1,982)$. Dengan demikian hipotesis yang diajukan bahwa terdapat berpengaruh signifikan antara prestasi kerja terhadap kinerja karyawan diterima.

\section{KESIMPULAN DAN SARAN}

\section{Kesimpulan}

a. Pelatihan berpengaruh signifikan terhadap prestasi kerja dengan kontribusi pengaruh sebesar 43,3\%. Uji hipotesis diperoleh nilai t hitung > t tabel atau $(9,163>1,982)$.

b. Kompensasi berpengaruh signifikan terhadap prestasi kerja dengan kontribusi pengaruh sebesar 33,6\%. Uji hipotesis diperoleh nilai t hitung $>\mathrm{t}$ tabel atau $(7,455>$ 1,982).

c. Pelatihan dan kompensasi secara simultan berpengaruh signifikan terhadap prestasi kerja dengan kontribusi pengaruh sebesar 52,4\% sedangkan sisanya sebesar 47,6\% dipengaruhi faktor lain. Uji hipotesis diperoleh nilai F hitung > F tabel atau $(59,987>$ 2,690).

d. Prestasi kerja berpengaruh signifikan terhadap kinerja karyawan dengan kontribusi pengaruh sebesar 40,0\%. Uji hipotesis diperoleh nilai t hitung > t tabel atau $(8,572>$ 1,982).

\section{Saran}

a. Perusahaan harus menambah frekuensi pelatihan, kelengkapan prasarana yang disesuaikan dengan jumlah peserta, kenyamanan dalam pelatihan serta ketepatanmateri pelatihan guna menunjang kemampuan karyawan.

b. Pimpinan harus mempertimbangkan pemberian kompensasi utamanya uang tranportasi dan asuransi yang masih minim.

c. Pimpinan harus terus mendorong karyawan agar meningktkan kualiatas pekerjaan agar mencapai target yang ditetapkan.

d. Saran bagi peneliti selanjutnya adalah agar dilakukan penelitian lanjutan yang lebih khusus atau dengan variabel baru, misalnya disiplin kerja, jaminan, kepuasan kerja 


\section{DAFTAR PUSTAKA}

Arikunto, Suharsimi (2014). "Prosedur Penelitian Suatu Pendekatan Praktek”. Jakarta: Rineka Cipta.

Edi Sutrisno (2016). Manajemen Sumber Daya Manusia. Jakarta: Prenadamedia Group. Freed Luthans (2016) Organizational Behavior, McGraw-Hill, New York.

Gerry Dessler (2016) Human Resources Management, Prenticehall, London: International Inc.

Goklas, A., et al. (2021). Management Of Organizational Performance: The Role Of Human Resource Management Strategy. Jurnal Ad'ministrare, 8(1), 245-254.

Handoko (2016) Manajemen Personalia dan Sumberdaya Manusia. Yogyakarta: BPFE.

Hasibuan (2016) "Manajemen Sumber Daya Manusia”. Haji Masagung. Jakarta.

Henry Simamora (2005), Manajemen Sumber Daya Manusia, STIE YKPN Bandung.

Imam Ghozali (2017). “Aplikasi Analisis Multivariate Dengan Program SPSS”. Edisi Kelima. Semarang: Badan Penerbit Undip.

Istijanto (2014) “Riset Sumber Daya Manusia”. Jakarta: PT. Gramedia Pustaka

Jasmani, J., \& Paeno, P. (2019). The Effect of Leadership and Competence on Lecturer Performance and Its Implications on Student Learning Motivation at Pamulang University. International Journal of Advances in Social and Economics, 1(4).

Juditya, S., et al. (2021). Digital Material Teaching: Learning Model and Learning Outcomes of Basketball. Journal of Educational Science and Technology (EST), 7(2), 134-140.

Kartini Kartono (2011) Pemimpin dan Kepemimpinan, Jakarta: PT. Rajawaligrafindo Persada.

Mangkunegara, Prabu Anwar. (2016). Evaluasi Kinerja SDM. Cetakan ke tujuh, PT Refika Aditama: Bandung.

Mani, J. (2018). Pengaruh Peran Nilai Pelanggan Dan Citra Merek Terhadap Kinerja Pemasaran. Jurnal Mandiri, 2(2), 263-280.

Manurung, A. H., et al. (2021). The Study of Human Resources Management Practice on Corporate Social Responsibility. Jurnal Ilmiah Ilmu Administrasi Publik, 11(1), 197-207.

Pranoto, P., Jasmani, J., \& Marayasa, I. N. (2019). Pelatihan Digital Marketing Untuk Peningkatan Perekonomian Anggota Karang Taruna Al Barkah Di Kampung Cicayur-Tangerang. Jurnal Pengabdian Dharma Laksana, 1(2), 250-258.

Purwanto, A., et al. (2021). Education Research Quantitative Analysis for Little Respondents. Jurnal Studi Guru Dan Pembelajaran, 4(2), 335-350.

Rivai Veithzal (2015) Manajemen Sumber Daya Manusia Untuk Perusahaan. Jakarta: PT Raja Grafindo Persada.

Santoso, Singgih (2015). "Menguasai Statistik Multivariat”. Jakarta: PT Elex Media Komputindo.

Sedarmayanti (2016) Manajemen Sumber Daya Manusia, Reformasi Birokrasi dan Manajemen Karyawan Negeri Sipil, Cetakan Kelima, Bandung: PT Refika Aditama.

Siagian, S (2007). Manajemen Sumber Daya Manusia. Jakarta: Bumi Aksara.

Sudjana (2014) "Metode Statistika”, Bandung: Tarsido.

Sugiyono (2017), "Metode Penelitian Administrasi : dilengkapi dengan Metode $R \&$ $D$ ". Bandung: Alfabeta.

Suwanto. Et al. (2021). Pengaruh Komunikasi Internal Dan Disiplin Kerja Terhadap Kinerja Karyawan Pada Bagian Produksi PT Adicipta Boga Intiprima Jakarta Pusat. Jurnal Tadbir Peradaban. 1(3). 222-229. 